\title{
Evaluation of gas wettability and its effects on fluid distribution and fluid flow in porous media
}

\author{
Jiang Guancheng ${ }^{1,2 *}$, Li Yingying ${ }^{1,2}$ and Zhang Min ${ }^{1,2}$ \\ ${ }^{1}$ State Key Laboratory of Petroleum Resources and Prospecting, China University of Petroleum, Beijing 102249, China \\ ${ }^{2}$ MOE Key Laboratory of Petroleum Engineering, China University of Petroleum, Beijing 102249, China \\ (C) China University of Petroleum (Beijing) and Springer-Verlag Berlin Heidelberg 2013
}

\begin{abstract}
The special gas wettability phenomenon of reservoir rocks has been recognized by more and more researchers. It has a significant effect on efficient development of unconventional reservoirs. First, based on the preferentially gas-covered ability and surface free energy changes, definition and evaluation methods have been established. Second, a method for altering rock wettability and its mechanisms have been studied, surface oriented phenomena of functional groups with low surface energy are the fundamental reason for gas wettability alteration of rock. Third, the effect of gas wettability on the surface energy, electrical properties and dilatability are investigated. Last, the effects of gas wettability on capillary pressure, oil/gas/water distribution and flow are investigated with capillary tubes and etchedglass network models. The gas wettability theory of reservoir rocks has been initially established, which provides theoretical support for the efficient production of unconventional reservoirs and has great significance.
\end{abstract}

Key words: Gas-wetting, fluorocarbon copolymer, contact angle, capillary pressure, surface free energy, surface property, fluid flow in porous media

\section{Introduction}

The wettability of rocks near boreholes is a key factor that determines the position, flow and distribution of reservoir fluids in porous media and has a great effect on the oilwater relative permeability and oil recovery (Morrow, 1990; Jiang, 1995; Ogunberu and Ayub, 2005; Wang et al, 2011). As early as 1942, Buckley and Leverett (1942) recognized the importance of wettability on water flooding performance. Later, some researchers studied the effect of wettability on capillary pressure, relative permeability, initial water saturation, residual oil saturation, oil recovery and electrical properties of reservoir rocks (Morris and Wieland, 1963; Donaldson and Thomas, 1971; Menezes et al, 1989; Cockcroft et al, 1989; Jia et al, 1991; Buckley et al, 1995). Other authors investigated the result of wettability adjustment on reservoirs and well stimulation such as oil displacement efficiency improvement during water flooding and oil recovery increase (Wagner and Leach, 1958; Froning and Leach, 1967; Kamath, 1970; Morrow et al, 1973; Penny et al, 1983).

Wagner and Leach (1958) reported that it is possible to improve oil displacement efficiency by wettability alteration

*Corresponding author. email: jgc5786@126.com

Received June 22, 2013 during water flooding. In 1967, Froning and Leach (1967) reported a field test in the Clearfork and Gallup reservoirs for improving oil recovery by wettability alteration. In 1983, Penny et al (1983) proposed a non-wetting approach (zero capillary pressure can be achieved by altering the watersolid contact angle to $90^{\circ}$ ) in fracturing treatments to control capillary pressure and enhance relative permeability. Their laboratory data and field applications showed impressive results: as employing this approach, due to longer frac lengths and higher fracture conductivities, the production following cleanup after fracturing in gas wells generally was 2 to 3 times greater than field averages or offset wells treated with conventional approaches. Zhou et al (1987) presented that the 'solid-gas wettability' was totally opposed to the solidliquid wettability. They believed that the more lyophobic the solid becomes, the easier the solid is 'wetted' by gas and for gas bubbles to attach to it; on the contrary, the more lyophilic of the solid, the easier it is to be wetted by liquid and harder for gas bubbles to attach to it. By utilizing this wettability differences between gas and liquid, valuable minerals and gangue can be separated and purified in froth flotation.

Although so many researchers have recognized the results of reservoir wettability alteration and its effects on well stimulation, it was not until 2000 that the special wetting phenomenon 'gas-wetting' was firstly put forward by Li and Firoozabadi (2000a). In their paper, by using a 
phenomenological simple network model, they suggested that the gas well deliverability in condensate reservoirs could be enhanced by wettability alteration to gas-wet near the wellbore. Later, they altered the wettability of porous media to preferentially gas-wet in laboratory by using two fluorochemicals, FC754 and FC722 (Li and Firoozabadi, 2000b).

Much attention has been paid to the study of this improved oil recovery (IOR) method. Tang and Firoozabadi (2000) used fluorochemicals to reduce the capillary pressure and enhance the liquid phase relative permeability of sandstone test core from Berea in Ohio and chalk samples by altering the wettability from liquid-wet to intermediately gas-wet. Their results showed that good wettability alteration occurred but the chemicals were limited to a maximum temperature of 90 ${ }^{\circ} \mathrm{C}$. A method was proposed by $\mathrm{Li}$ and Horne (2003) in 2003 to evaluate the wettability in both gas/liqui/drock system and liquid/liquid/rock system. This method can be used to evaluate the wettability at specific wetting phase saturation if the capillary pressure and relative permeability at this fluid saturation are known. In the work of Panga et al (2006), five different chemicals (A1-A5) were evaluated for their ability to prevent water block formation at high temperatures by testing the contact angle and air-brine imbibition (the chemicals A1-A3 are surfactant based, A4 is a fluoropolymer and A5 is a fluorotelomer). They tested 41 chemicals with the same methods in 2007, and the results showed that the fluorotelomer A5 gave the best effect of wettability alteration at high temperatures with minimum formation damage, and a solution containing $5 \% \mathrm{~A} 5$ and $95 \%$ brine $(2 \mathrm{wt} \% \mathrm{KCl})$ gave higher cleanup of trapped water due to reduction in capillary forces (Panga et al, 2007). Liu et al (2006) altered core samples, which derived from the Dongpu gas-condensate reservoir from water-wet to gas-wet effectively by a new and cheap chemical WA12 (a fluorocarbon surfactant), which is stable up to $170{ }^{\circ} \mathrm{C}$. Experimental results demonstrated that the relative permeability to both the gas and water phases increased significantly after wettability alteration to preferentially gas-wet, and the residual water saturation decreased. The fluorocarbon surfactant WA12 was applied to a gas condensate well in Dongpu field in 2008 and it was found that the gas production increased significantly but the increase in gas production was not sustained (Liu et al, 2008). Al-Anazi et al (2007) evaluated the gas wettability alteration effectiveness of various fluorochemicals and silanes on carbonate and sandstone reservoir cores and Berea test cores by core flooding experiments under simulated reservoir conditions. The results showed that the effectiveness of chemicals is affected by treatment volume, aging time, core permeability, temperature, and treatment constituents. In 2005, Fahes and Firoozabadi (2005) reported two fluorochemicals, 11-12P and L-18941, manufactured by $3 \mathrm{M}$ Company, could achieve gas wettability alteration at high temperatures $\left(140{ }^{\circ} \mathrm{C}\right)$, and did not have a measurable effect on the absolute permeability of the rock. Then Noh and Firoozabadi (2008) tested the effectiveness of other chemicals manufactured by 3M Company, 11-12P and L-19062 in 2008. The treatments with 11-12P and L-19062 provide significant improvement on both water and oil phase mobility, and the improved mobility of oil is much less pronounced than that of water. In 2008, Yao et al (2008) evaluated the capability of five kinds of chemicals (dodecyl benzene sulfonate, cetyl trimethyl ammonium bromide, OP-15, GB-201 and DMS), concerning the gas wettability alteration of artificial sandstone cores with the methods of capillary rise, Washburn equation and spontaneous imbibition through wetting angle determination. GB-201 could achieve preferential gas wettability alteration from water-wet and oil-wet, which led to an increase in relative permeability to the liquid phase and a decrease in liquid saturation. In the work of Shao et al (2010a; $2010 \mathrm{~b}$ ), the effect of pore-throat ratio, rock wettability, initial water saturation and residual water saturation on relative permeability were carried out, by using the methods of pore network simulated with the throat radius varying from 0.05 to $2.50 \mu \mathrm{m}$. They discovered that when water saturation is higher than 0.4 , the gas relative permeability increased in the order water-wet $\rightarrow$ weakly water-wet $\rightarrow$ weakly gas-wet $\rightarrow$ gas wet sequentially. However, the above order would be shuffled when water saturation is lower than 0.4. In 2012, a fluorinecontaining acrylate copolymer emulsion was prepared with butyl acrylate and perfluoro acrylate as monomers by Feng et al (2012). Experimental results of contact angle (CA), capillary rise and spontaneous imbibition demonstrated that the copolymer emulsion could alter the wettability of porous media from strongly liquid-wet to gas-wet.

Many researchers have investigated gas wettability alteration and its effects on well stimulation, but they have not provided information on the mechanism of gas wettability alteration and its effects on several aspects which closely relate to rock properties. To this end, we embarked on series of comprehensive studies on gas wettability, which include evaluation methods, chemical mechanism of wettability alteration, and the effects on other properties of porous reservoirs.

\section{Definition and evaluation methods of gas wettability}

\subsection{Definition of gas wettability}

Generally, gas is taken as a non-wetting phase in the petroleum industry (Krasowaka et al, 2009). As the longrange force between gas and lyophobic surfaces existing in the liquid phase has been recognized and investigated in recent years, more and more attention has being paid to gas wettability (Briant and Cuiec, 1971; Zhu and Zhao, 1996). The essence of wettability is that in a solid-liquidliquid system, the initially wetting phase is displaced by the preferentially wetting phase and then the Gibbs free energy of this system decreases (Briant and Cuiec, 1971). In other words, it is presented as the Gibbs free energy decreasing and a weakly wetting phase being displaced by a preferentially wetting phase. Hence, the gas wettability is defined as the displacement ability of the gas phase over the liquid phase in a gas/liquid/solid system, and this may reduce the surface free energy of the solid.

\subsection{Establishment of evaluation methods}

Conventional methods for wettability evaluation 
are commonly used at present. However, as the gas is characterized by low viscosity and high compressibility, whether evaluation methods used for liquid wettability measurement are suitable for gas wettability measurement or not, is a subject urgently needing to be discussed. In this paper, the gas wettability evaluation methods were established based on the conventional evaluation methods, which involved gas phase-contact angle.

\subsubsection{Sessile drop method}

After dripping a liquid droplet on the solid surface in the gas phase, the spreading of the droplet is a process of liquid and gas covering the solid surface competitively, and it is also a process of the liquid wetting the solid surface over gas. The smaller the contact angle $\left(\theta_{1}\right)$ of the droplet on the solid surface is, the easier it is to be wetted by the liquid phase and the harder it will be to be wetted by gas (Shown in Fig. 1).

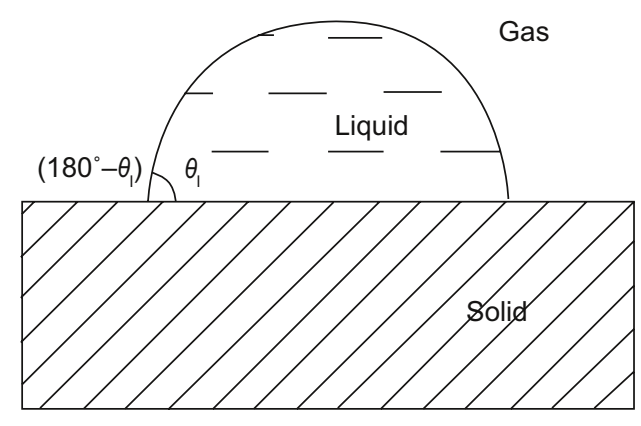

Fig. 1 Sessile drop of liquid on solid surface

Therefore, the supplement of the droplet contact angle $\left(180^{\circ}-\theta_{1}\right)$ is able to be used as an evaluation parameter for the gas wettability over liquid. The gas wettability degree over a given liquid could be parameterized with $\zeta_{\mathrm{g}-1}$, which is defined as follows:

$$
\zeta_{\mathrm{g}-1}=\cos \left(180^{\circ}-\theta_{1}\right)
$$

Fig. 2 indicates that the gas wettability is improved along with an increases in $\zeta_{\mathrm{g}-1}$ and $\theta_{1}$. The quantitative evaluation indices of gas wettability are shown in Table 1 .

Table 1 Quantitative evaluation indices of the sessile drop method

\begin{tabular}{ccc}
\hline $\begin{array}{c}\text { Contact angle of } \\
\text { liquid } \theta_{1} \text {, degree }\end{array}$ & $\begin{array}{c}\text { Gas wettability } \\
\text { parameter } \zeta_{\mathrm{g}-1}\end{array}$ & Gas wettability \\
\hline$(90,180]$ & $(0,1]$ & Preferentially gas-wet \\
90 & 0 & Intermediately gas-wet \\
{$[0,90)$} & {$[-1,0)$} & Non-gas-wet \\
\hline
\end{tabular}

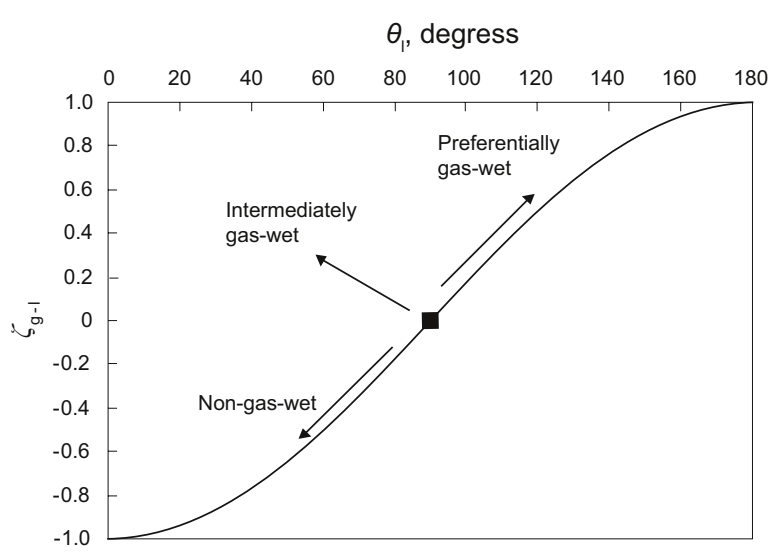

Fig. 2 Relation between gas wettability $\zeta_{\mathrm{g}-1}$ and $\theta_{1}$

\subsubsection{Captive bubble method}

The captive bubble method is commonly used to assess liquid wettability, which measures the liquid contact angle by the bubble shape existing on the solid/liquid interface. As the change of the bubble shape is affected by the degree of gas wettability of the solid surface, a stable bubble on the solid/ liquid interface is measured with the captive bubble method to assess the degree of gas wettability (Shown in Fig. 3).
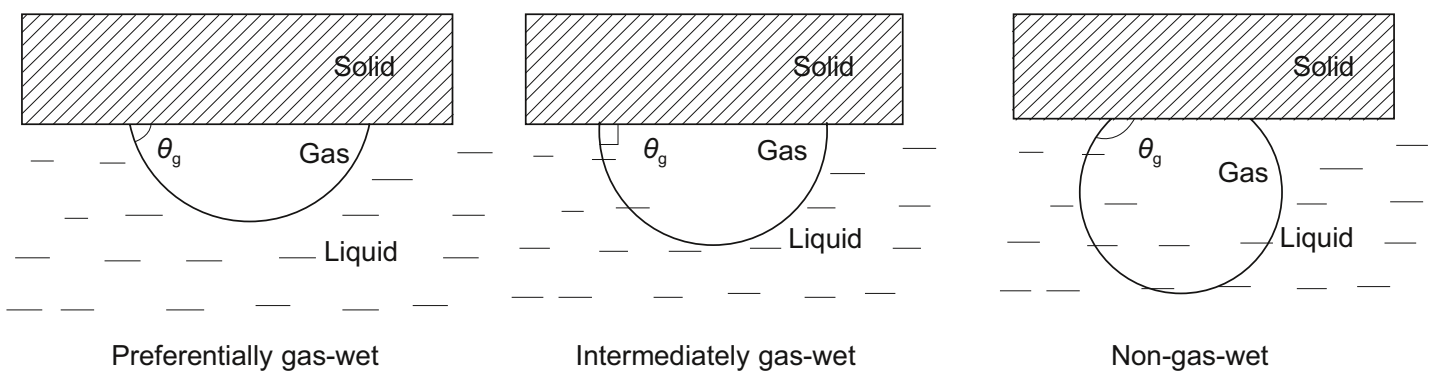

Fig. 3 Absorption of bubbles on different gas-wet surfaces

The supplement of the liquid contact angle is defined as the gas contact angle, $\theta_{\mathrm{g}}$, which represents the degree of gas wettability of the solid surface in this liquid. Several indices listed in Table 2 are used to evaluate gas wettability in the captive bubble method.
Table 2 Quantitative evaluation indices used in the captive bubble method

\begin{tabular}{cc}
\hline Contact angle of gas $\theta_{\mathrm{g}}$, degree & Gas wettability \\
\hline$[0,90)$ & Preferentially gas-wet \\
90 & Intermediately gas-wet \\
$(90,180]$ & Non-gas-wet \\
\hline
\end{tabular}


The sessile drop method and the captive bubble method have their own characteristics and applicability, the former estimates gas wettability through the wettability of the liquid phase, and the latter assesses gas wettability directly by the shape of the captive bubble. The sessile drop method is a process in which the solid/liquid interface is displaced by the solid/gas interface, and the captive bubble method is an opposite displacement process. These two methods can evaluate gas wettability quantitatively and effectively, which has been verified by some experiments.

\subsection{Factors affecting gas wettability}

Surface free energy and test materials are the main factors affecting gas wettability.

The gas wettability both in gas/water and gas/oil systems increases along with a decrease in the surface free energy of the solid. On a solid surface, a smaller liquid surface free energy indicates this solid is better liquid-wet and worse gaswet. Only when the surface free energy of the solid is smaller than that of a certain liquid, is the solid surface preferentially wetted by gas over this liquid; and the smaller the solid surface free energy, the stronger the gas wettability.

In the gas phase, water and oil have the same variation of wettability on different test materials; and the smaller the material surface free energy, the bigger the liquid contact angle (Zisman, 1964). As the degree of gas wettability is enhanced along with hydrophobic and oleophobic ability, as a result of surface free energy decrease, the gas wettability to water was stronger than that to oil on the same material, for oil-wet was stronger than water-wet on a certain solid material surface.

The gas contact angle has the same trend in both water and oil phases, and the gas-solid contact angle in the water phase was smaller than that in the oil phase. Therefore, the gas wettability was stronger in water than in oil.

\section{Preparation of gas-wet samples and mechanisms of gas wettability alteration}

\subsection{Synthesis of gas wettability alteration chemical FC-1}

Li and Firoozabadi (2000b) used fluorochemical FC722 to alter rock wettability from liquid-wet to preferentially gas-wet. The fluorochemical FC722 had a pronounced effect for wettability alteration to preferentially gas-wet, but its low solubility limited the application on wettability alteration due to the high costs of introducing a solvent to dissolve it. In later research on gas wettability alteration, fluorocarbon products manufactured by $3 \mathrm{M}$ Company were used as wettability alteration chemicals. The field application of these fluorocarbon products was limited not only by the high material cost, but also by environmental restrictions. When the carbon number in fluorocarbon chains is greater than or equal to 8 , the degradation products of fluorocarbon products, such as PFOA and PFOS are detrimental to human body and environment and have been banned by many countries. In 2012, a fluoroacrylate copolymer, was randomly copolymerized by batch feeding, and used to change the rock wettability from liquid-wet to gas-wet by multipoint adsorption (Feng et al, 2012). However, in this synthesis method, a lot of expensive fluoroacrylate monomers were required to achieve high monomer concentration and realize gas-wet with this one-batch feeding method.

To this end, a novel and suitable chemical FC-1, which contains acrylate and fluorinated acrylate monomers, was synthesized by core-shell copolymerization and in the copolymerization process, the raw materials were fed in two batches. The resultant product is soluble in water, less expensive and of good ability for wettability alteration.

Various monomers were chosen for various purposes. Methyl methacrylate (MMA) and methacrylic acid (MAA) would provide strength and weatherability to the copolymer, and hydrophilic groups in MAA were also introduced, which promoted the adhesion of the copolymer to rock. The addition of butyl acrylate (BA) increased the elasticity and flexibility of the copolymer. A fluoroacrylate with 6 carbon atoms and 13 fluorine atoms in fluorocarbon chains was selected for polymerization. When the carbon number in fluorocarbon chains is lower than or equal to 6 , the products are not bioaccumulative or harmful to the human body and environment (Lehmer, 2007). The methyl side chains in monomers could enhance the glass transition temperature of the copolymer and promote the crystallization of perfluorinated side chains $-\left(\mathrm{CF}_{2}\right)_{5} \mathrm{CF}_{3}$ by reducing the activity of the backbone and side chains.

BA, MMA and MAA were slowly added into the surfactant solution of SDS (sodium dodecyl sulfate), and the mixture was made into a homogeneous emulsion with a shear emulsification mixer. The emulsion was transferred into a four-neck flask equipped with an electric mixer, condensing tubes, a nitrogen import device and an $80^{\circ} \mathrm{C}$ water-bath. The initiator, ammonium persulfate (APS), was dripped into the flask twice at 65 and $75{ }^{\circ} \mathrm{C}$ respectively, and the polymerization time was 30 minutes. The fluoroacrylate, SDS and APS were slowly dripped into the emulsion, and the polymerization time was 4 hours. The emulsion was allowed to cool and the $\mathrm{pH}$ was adjusted to 7 with $\mathrm{NaHCO}_{3}$ (sodium bicarbonate), and then the gas wettability alteration chemical, named FC-1, was obtained.

Artificial sandstone cores (diameter 24.60-24.75 mm, length 49.75-50.50 mm, permeability 48.34-52.70 mD, porosity $11 \%-13 \%$ ) were used to simulate natural cores. Artificial sandstone cores were immersed in FC-1 solutions (solutions containing 2\%,4\%,6\%,8\% and 10\% FC-1 and distilled water) for 4 hours, and after 4 hours of immersion the cores were first dried at room temperature and then at $100{ }^{\circ} \mathrm{C}$ in an electrical thermostatic oven. The contact angles of distilled water and hexadecane on the core surfaces were measured respectively before and after treatment with a JC2000D3 contact angle meter, and the results are shown in Table 3.

Due to the synergistic effect of all the monomers above, FC-1 had good wettability alteration characteristics. The wettability of the core surface altered from liquid-wet to preferentially gas-wet gradually along with the FC-1 dosage. 
Table 3 Contact angle of FC-1 treated cores

\begin{tabular}{ccc}
\hline \multirow{2}{*}{$\begin{array}{c}\text { FC-1 concentration } \\
\%\end{array}$} & \multicolumn{2}{c}{ Contact angle, degree } \\
\cline { 2 - 3 } 2 & 115 & Dexadecane \\
\hline 4 & 120 & 70 \\
6 & 124 & 75 \\
8 & 123 & 83 \\
10 & 125 & 97 \\
\hline
\end{tabular}

After being treated with 10\% FC-1 solution and aged for 12 hours at $100{ }^{\circ} \mathrm{C}$, the core surface had a contact angle with water of $125^{\circ}$ and a contact angle with hexadecath of $97^{\circ}$, respectively, the images (digital photographs) of wettability alteration effect and differences in contact angles are shown in Fig. 4 (treated with 10\% FC-1 solution).

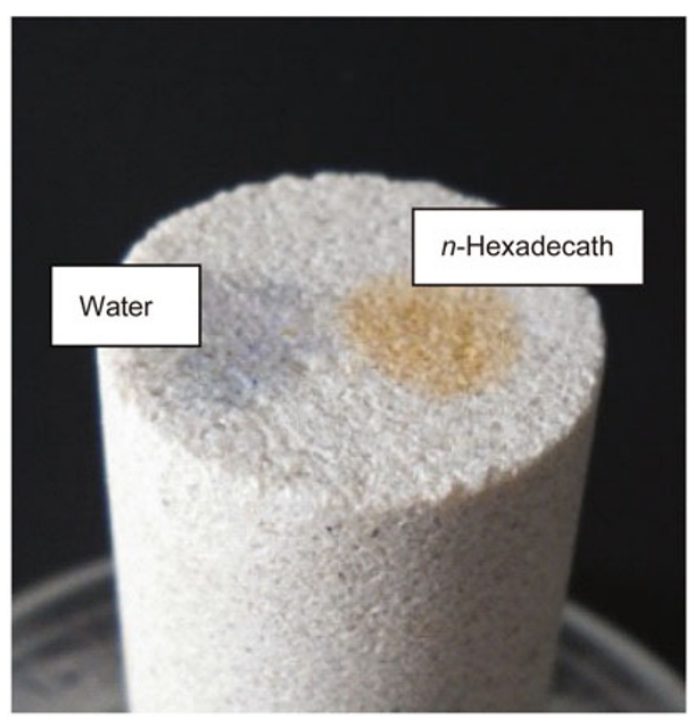

(a) Liquid-wet core sample

\subsection{Mechanism of wettability alteration}

The microstructure and distributions of elements and functional groups of the FC-1 latex film, FC-1-treated cores and quartz glass slides were examined with a transmission electron microscope (TEM), a scanning electron microscope (SEM) and an X-ray photoelectron spectrometer (XPS).

Artificial sandstone cores (diameter 24.60-24.75 mm, length 49.75-50.50 mm, permeability 48.34-52.70 mD, porosity $11 \%-13 \%$ ) were used to simulate natural cores in the SEM detection. Artificial sandstone cores were cut into slices, and the slice surfaces were polished with abrasive paper and then immersed in the $10 \% \mathrm{FC}-1$ solution for 4 hours. After 4 hours of immersion the cores were first dried at room temperature and then at $100{ }^{\circ} \mathrm{C}$ in an electrical thermostatic oven. The surface appearance of core slices were examined before and after FC-1 solution treatment (FC1 adsorption on the surface of core slice) with the Quanta 200F scanning electron microscope, and the energy spectrum was also analyzed (at least 5 small areas in each test sample

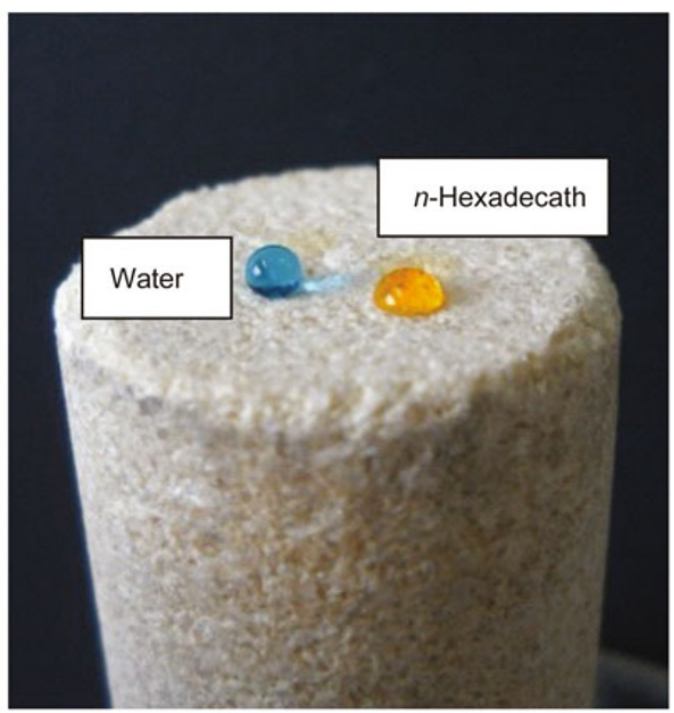

(b) Gas-wet core sample

Fig. 4 Contact angles of liquid-wet and gas-wet core samples before and after treatment with $10 \%$ FC-1 solution

were chosen and the average element content was obtained in energy spectrum detection).

The fluorine content of the surface of the FC-1 treated core slice by SEM energy dispersive X-ray analysis was much higher than the theoretical value (the calculation was based on the synthetic formula), which indicated that the fluorinated functional groups with low surface energy had a strong tendency to move to the surface. This surface oriented phenomenon in the filming process made the fluorine content different and decreased the surface free energy, and the wettability of the core sample altered to preferentially gaswet (Fig. 5 and Table 4).

The surface appearance and element distribution of core samples varied greatly after adsorption of FC-1, as shown in Fig. 6 and Table 5. The surface of the artificial core samples was mainly composed of big particles and pores. The main elements were silicon and oxygen, and there was no fluorine element. The natural core sample was lyophilic because of chemical composition and capillary force. After being treated with the FC-1 solution, the FC-1 was adsorbed on the

Table 4 Theoretical and actual contents of fluorine

\begin{tabular}{ccc}
\hline \multirow{2}{*}{\begin{tabular}{c} 
Content of fluoroacrylate $\begin{array}{c}\text { Fluorine content, \% } \\
\text { monomer, } \%\end{array}$ \\
\cline { 2 - 3 }
\end{tabular}} & $\begin{array}{c}\text { Theoretical content } \\
\text { by calculation }\end{array}$ & $\begin{array}{c}\text { Actual content } \\
\text { by SEM measurement }\end{array}$ \\
\hline 5 & 2.40 & 9.7 \\
10 & 4.60 & 16.3 \\
15 & 6.63 & 20.3 \\
20 & 9.10 & 30.0 \\
\hline
\end{tabular}




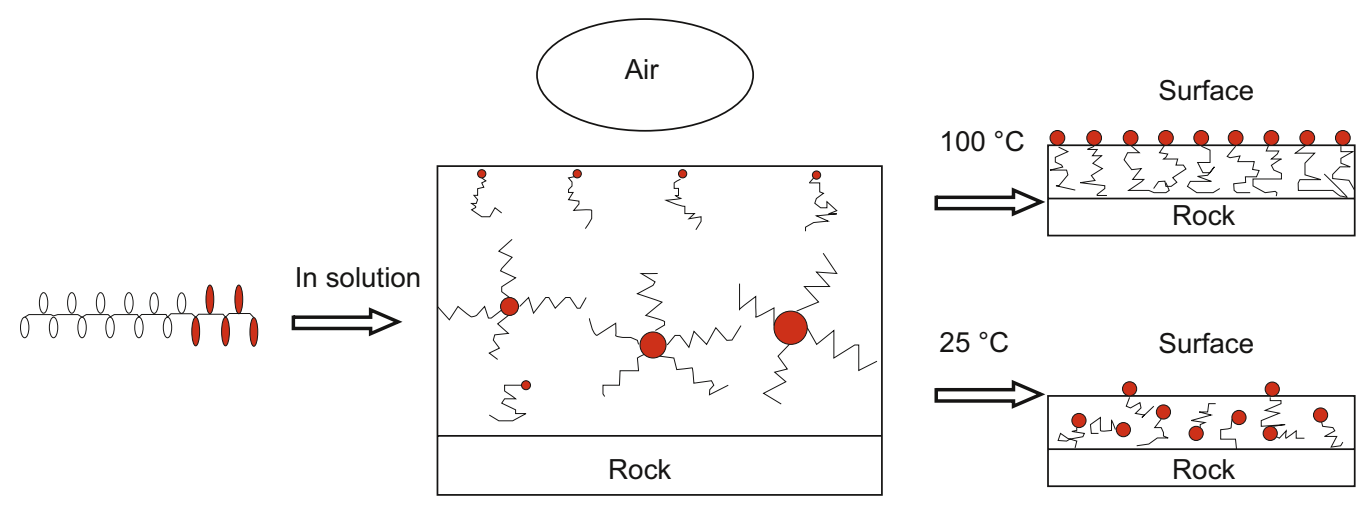

Fig. 5 Surface oriented phenomena of functional groups with low surface energy

core surface and built a film, which made the core porosity decreased, the oxygen content dropped to $13.9 \%$, but the fluorine content increased up to $9.7 \%$. Fig. 6 and Table 5 indicate that the wettability of core sample had been altered to gas-wet due to the modification by low surface energy chemical FC-1.

The microstructure of functional groups of the FC-1 latex film was examined with the JEM-2100 LaB6 transmission electron microscope (TEM). FC-1 was dissolved with alcohol (a solution containing 5\% FC-1 and 95\% alcohol) and dispersed by ultrasonic for 40 minutes, then dripped a drop of the solution on the testing carbon film and dried at room temperature, and detected the microstructure of the testing samples with the JEM-2100 LaB6 transmission electron microscope (TEM).

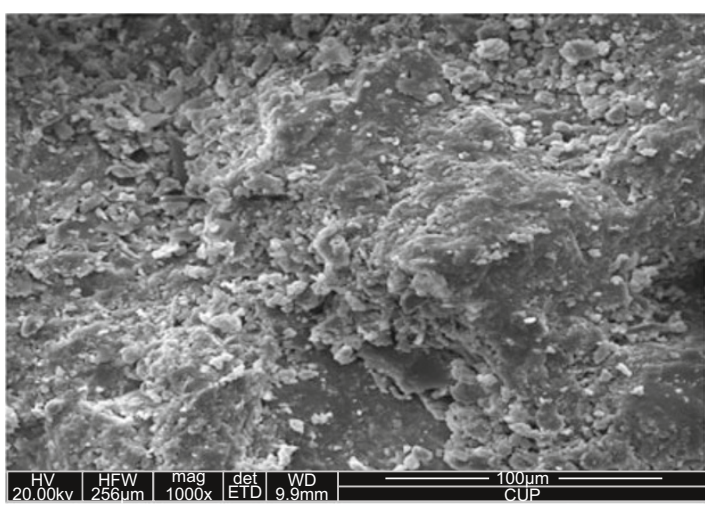

(a) Before being treated with the FC-1 solution
Table 5 Element differences

\begin{tabular}{ccccccc}
\hline \multirow{2}{*}{ Element } & \multicolumn{2}{c}{ Untreated core sample } & & \multicolumn{2}{c}{ Treated core sample } \\
\cline { 2 - 3 } \cline { 5 - 6 } & $\mathrm{Wt} \%$ & $\mathrm{At} \%$ & & $\mathrm{Wt} \%$ & $\mathrm{At} \%$ \\
\hline $\mathrm{O}$ & 27.2 & 40.67 & & 13.9 & 22.31 \\
$\mathrm{~F}$ & 0 & 0 & & 9.7 & 13.13 \\
$\mathrm{Na}$ & 2.11 & 2.20 & & 2.7 & 3.08 \\
$\mathrm{Al}$ & 10.4 & 9.20 & & 14.5 & 13.81 \\
$\mathrm{Si}$ & 48.3 & 41.19 & & 41.8 & 38.26 \\
$\mathrm{~K}$ & 4.1 & 2.51 & & 4.1 & 2.73 \\
$\mathrm{Fe}$ & 5.3 & 2.27 & & 5.0 & 2.28 \\
\hline
\end{tabular}

Notes: $\mathrm{Wt} \%$ - weight percentage, $\mathrm{At} \%$ - atomic percentage

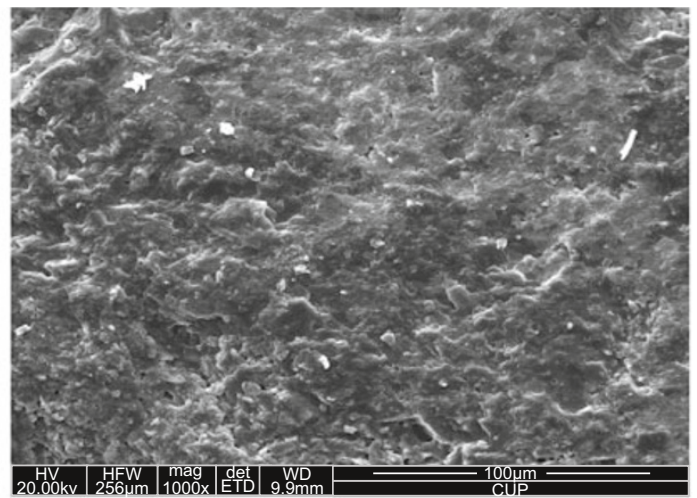

(b) After being treated with the FC-1 solution

Fig. 6 SEM images illustrating surface appearance alteration (artificial sandstone cores)

The atomic arrangement of FC-1 was very regular and had apparent anisotropic crystal characteristics (Fig. 7). A neat mesh structure was formed on the surface of carbon film used in the TEM detection, and the fluorocarbon side chains orderly occupied the polymer/air interface, which made the treated solid surface exhibit low-energy characteristics and alter from liquid-wet to preferentially gas-wet.

The FC-1-treated glass slides were examined with the $\mathrm{X}$-ray photoelectron spectrometer (XPS). The quartz glass slides are immersed in the $10 \%$ FC-1 solution for 4 hours and cleaned with distilled water and ultrasonic. Then the quartz glass slides were dried at room temperature and then

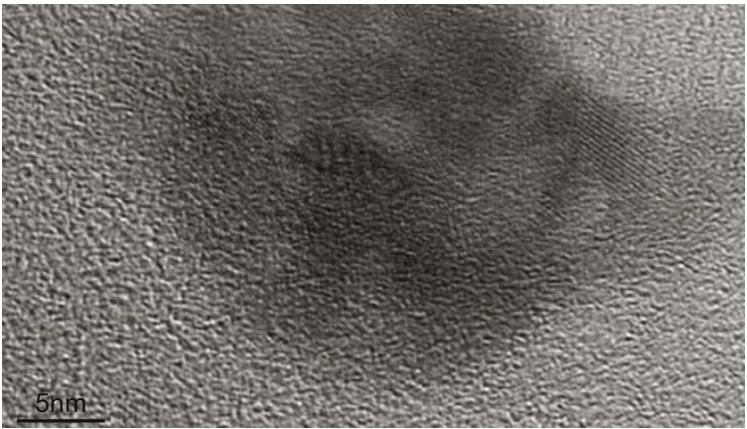

Fig. 7 Transmission electron microscopy (TEM) image of FC-1 latex film 
at $100{ }^{\circ} \mathrm{C}$ in an electrical thermostatic oven. The testing samples were then examined with the X-ray photoelectron spectrometer (XPS).

The X-ray photoelectron spectra (XPS) of an FC-1-treated glass slide showed that the main groups in the FC-1 film

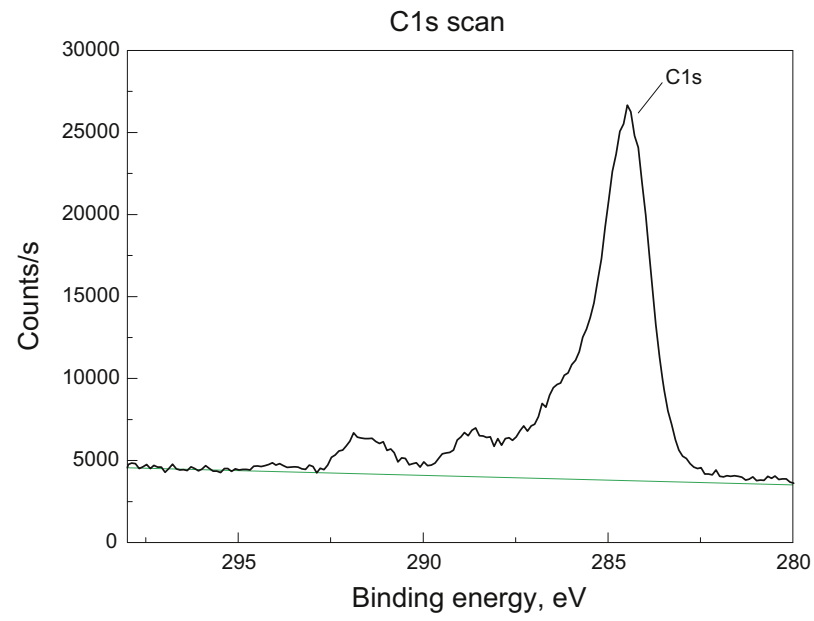

(a) Spectrum of carbon sources of a few to several tens of nanometers were $-\mathrm{CF}_{3},-\mathrm{CF}_{2}$, $-\left(\mathrm{CF}_{2}\right)_{n},-(\mathrm{C}-\mathrm{C})_{n}$ and $-\left(\mathrm{CF}_{2} \mathrm{CFH}\right)_{n}$. There was no absorption peaks of $-\mathrm{CH}_{3},-\mathrm{CH}_{2},-\left(\mathrm{CH}_{2}\right)_{n},-\mathrm{COOH}$, which indicated that the internal polar groups were protected firmly by the fluorocarbon film (Fig. 8).

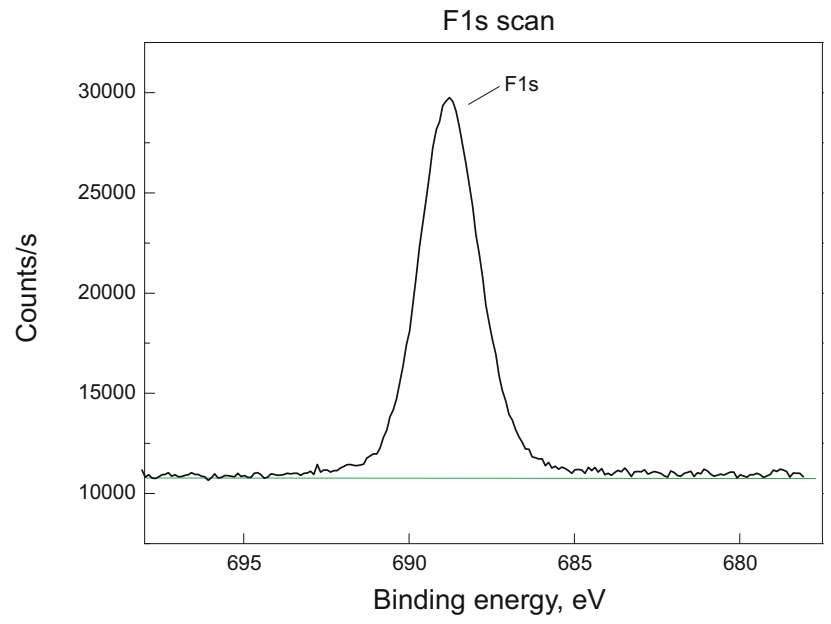

(b) Spectrum of fluorine sources

Fig. 8 XPS of FC-1-treated glass slides

\section{Effect of gas wettability on rock surface properties}

\subsection{Dispersion properties of clay minerals in rock samples}

Wettability alteration of rocks was bound to affect the dispersion properties of clay minerals in reservoir rocks. After chemical FC-1 was adsorbed on montmorillonite (MMT), zeta potential, dilatability and cation exchange capacity (CEC) of the MMT samples were studied, and its mechanisms were also analyzed. The purity of the MMT sample was $91 \%$, containing a little kaolinite and illite.

Several grams of 100-200 mesh and 200-400 mesh MMT were immersed in the FC-1 solution with different concentrations for 4 hours. After the chemical was fully absorbed on the MMT surface, the mixture was placed in an $105^{\circ} \mathrm{C}$ oven for drying for 24 hours, then ground and cooled at room temperature of $25^{\circ} \mathrm{C}$. This was the gas-wet MMT.

The gas-wet MMT was added to a container filled with distilled water. This suspending liquid was stirred for $5 \mathrm{~min}$ at a high speed, and then was diluted to a concentration of $0.05 \%$ after being stirred for $30 \mathrm{~min}$ and kept still for 24 hours. A ZetaSizer NanoZS was used to test the zeta potential. All experiments were performed at room temperature $\left(22 \pm 3{ }^{\circ} \mathrm{C}\right)$, and the $\mathrm{pH}$ value of suspending liquid was about 7 .

The dispersion of clay minerals could be divided into four grades based on zeta potential, i.e. extreme dispersion, high dispersion, possible dispersion and non-dispersion, corresponding to zeta potential of $-60,-40,-20$ and $-10 \mathrm{mV}$, respectively.

When the FC-1 concentration increased, the zeta potential of MMT increased gradually and transition from high dispersion to possible dispersion. When the concentration of FC-1 eventually reached $100 \%$, the zeta potential rose to $17.27 \mathrm{mV}$ and the FC-1-treated MMT was in a non-dispersed state (Fig. 9).

Under the same conditions of altering core wettability, the rate of increase of zeta potential of 200-400 mesh MMT was higher than that of 100-200 mesh MMT. The reason may be that the surface area of 200-400 mesh MMT was large and the wettability alteration chemical was adsorbed to form a membrane, so that the reduction in negative charges on the MMT surface resulted in an increase in zeta potential, as shown in Fig. 9.

The cation exchange capacity (CEC) of MMT was estimated by its methylene blue capacity (MBC). A 4\% MMT suspension was prepared with distilled water and then kept still for 24 hours. $2 \mathrm{~mL}$ MMT suspension was added to a

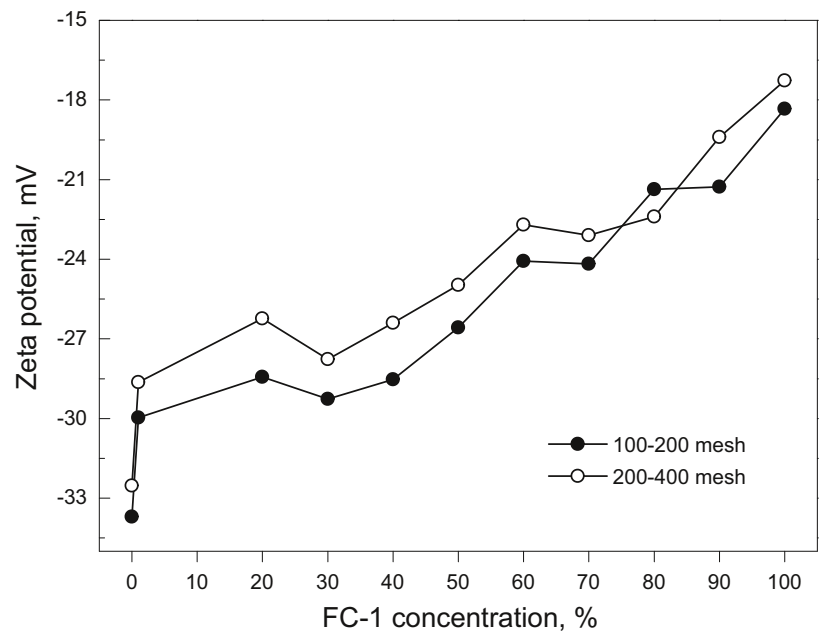

Fig. 9 Relation between the FC-1 concentration and the zeta potential 
conical flask with $10 \mathrm{~mL}$ distilled water. Then $15 \mathrm{~mL} \mathrm{3 \%}$ $\mathrm{H}_{2} \mathrm{O}_{2}$ solution and $0.5 \mathrm{~mL}$ sulfuric acid $(2.5 \mathrm{~mol} / \mathrm{L})$ were added to the flask. The mixture was slowly heated to boiling and kept gently boiling for $10 \mathrm{~min}$, and then diluted with distilled water to $50 \mathrm{~mL}$.

$0.5 \mathrm{~mL}$ methylene blue solution $(0.01 \mathrm{~mol} / \mathrm{L})$ was dripped into the mixed MMT suspension and the flask shaken for 30 seconds. A drop of suspension was dripped on a filter paper with a stirring rod. When the dye showed a turquoise ring around the dyed solid, the end point of titration has been reached. When the turquoise ring extended outward from spots, we shook the conical flask for $2 \mathrm{~min}$ and then put another drop of suspension on the filter paper. If the turquoise ring was still apparent, it has reached the ending. Otherwise, previous operations were continued until a ring appeared on the filter paper. The MBC is calculated according to Eq. (2).

$$
M B C=\frac{V_{\mathrm{m}}}{V}
$$

where $M B C$ is the methylene blue capacity; $V_{\mathrm{m}}$ is the methylene blue consumption, $\mathrm{mL} ; V$ is the sample volume, $\mathrm{mL}$.

The values of methylene blue capacity (MBC) dropped from 2.1 to 0.2 , which indicates that the cation exchange capacity (CEC) declined sharply with an increase in the FC-1 concentration (Fig. 10). It is obvious that the CEC of the gaswet MMT declined and its stability was improved. The reason may be that FC-1 was adsorbed on the MMT surface to form a stable film, which protected the internal negative charges and prevented neutralization reaction of cations and negative charges. This is similar to the reason why the zeta potential changes.

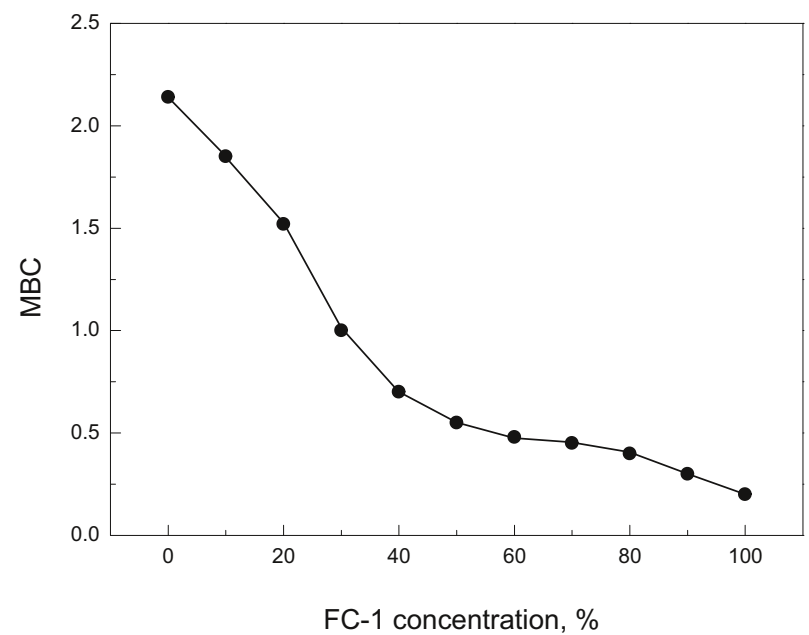

Fig. 10 Relation between FC-1 concentration and MBC

The dilatability of gas-wet MMT decreased along with an increase in the FC-1 concentration (Fig. 11). When the FC-1 concentration reached $100 \%$, the expansion height of MMT was only $0.83 \mathrm{~mm}$. The dilatability of MMT reduced significantly after wettability alteration, because a stable shielding film of FC-1 was formed on the surface of MMT, which prevented water from entering the crystal layers and giving rise to hydration expansion.

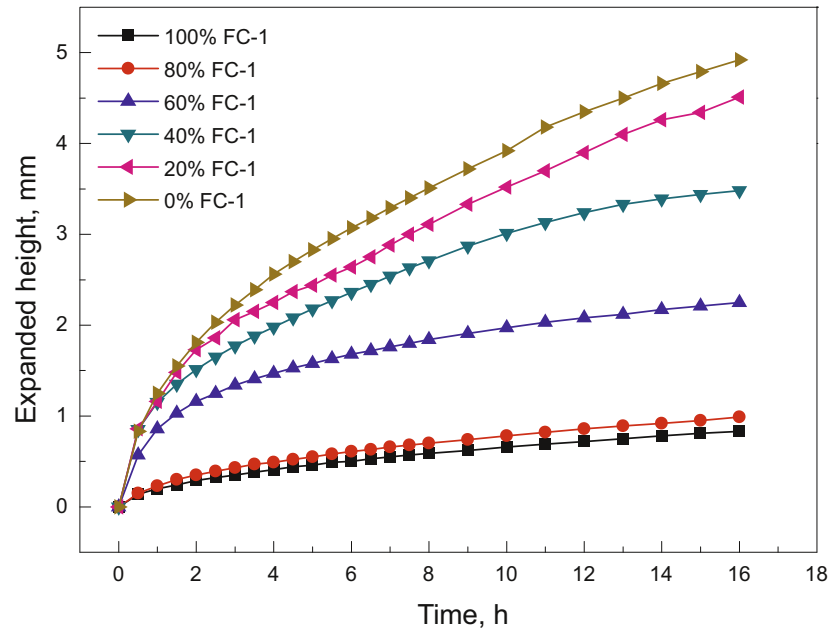

Fig. 11 Dilatability of the FC-1-treated MMT

\subsection{Electrical properties of rock samples}

Wettability alteration would affect the location and distribution of fluids in rock pores, thus the rock electrical properties would be changed and the electric logging accuracy was sure to be affected (Anderson, 1986; Chen and Monger-McClure, 1995). The effect of wettability alteration on core resistivity and gas saturation were investigated, and the relation between gas-wetting and core resistivity was also studied.

The resistivity of core samples after displacement with FC-1 solution varied more widely than that of core samples saturated by simulated formation water. The core resistivity increased significantly at low frequency ranges, reaching $56,884 \Omega \cdot \mathrm{m}$ (Fig. 12). The simulated formation water was an electrolytic solution, which had a good conductivity; while the wettability alteration chemical FC-1 was fluoroacrylate copolymer and the conductivity of its aqueous solution was weak. As the FC-1 solution was driven into the core pores, the cross sectional area that the electrical currents passed through reduced and the length of the conductive path increased for the core matrix was almost non-conductive; so the resistivity of core samples was much higher than that of the FC-1 solution with the same volume.

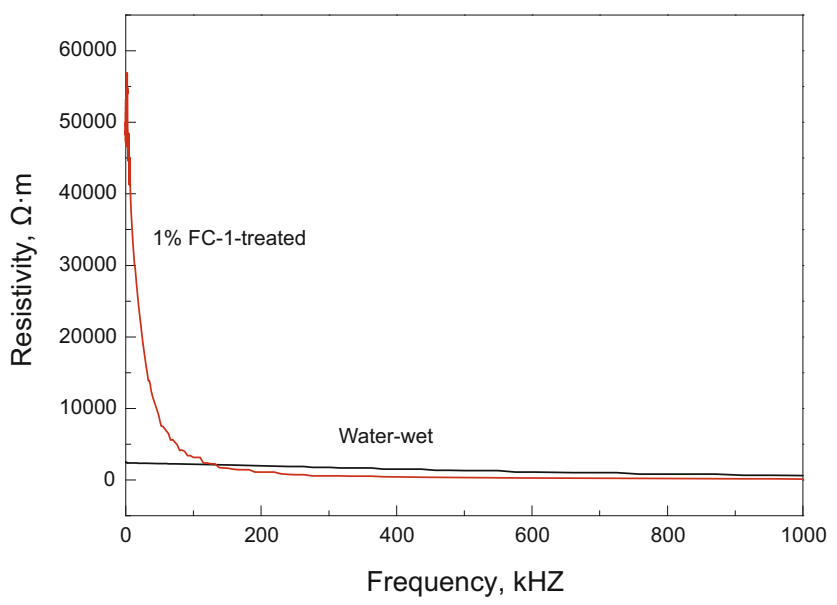

Fig. 12 Core resistivity at different frequencies 
The resistivity variation of water-wet and gas-wet core samples saturated with simulated formation water were similar, that is, the resistivity of both types of core samples decreased as the frequency increased and the difference between them was not significant (Fig. 13). It was clear that the conductive path was continuous water in the connected pores under high water saturation conditions. The resistivity mainly depended on the salinity of the simulated formation water and the pore structures; so the resistivity differences between water-wet and gas-wet core samples were not significant under high water saturation conditions.

When the gas saturation of core samples was very low, the simulated formation water in core pores was the continuous phase and the resistivity was low too. When the gas saturation increased, the rock wettability markedly affected the rock resistivity. For the water-wet core samples, the resistivity increased gradually as the gas saturation increased. When the gas saturation was more than $40 \%$, unstable water droplets were formed in the continuous water in pores, and then the conductive path was broken, so the resistivity increased sharply. The gas saturation at this point is called critical gas saturation. Similar to the water-wet core samples, the resistivity of the gas-wet core samples increased rapidly when the gas saturation was about $40 \%$, because the conductive path in the simulated formation water was destroyed (Fig. $13)$.

Under the condition of irreducible water saturation, the

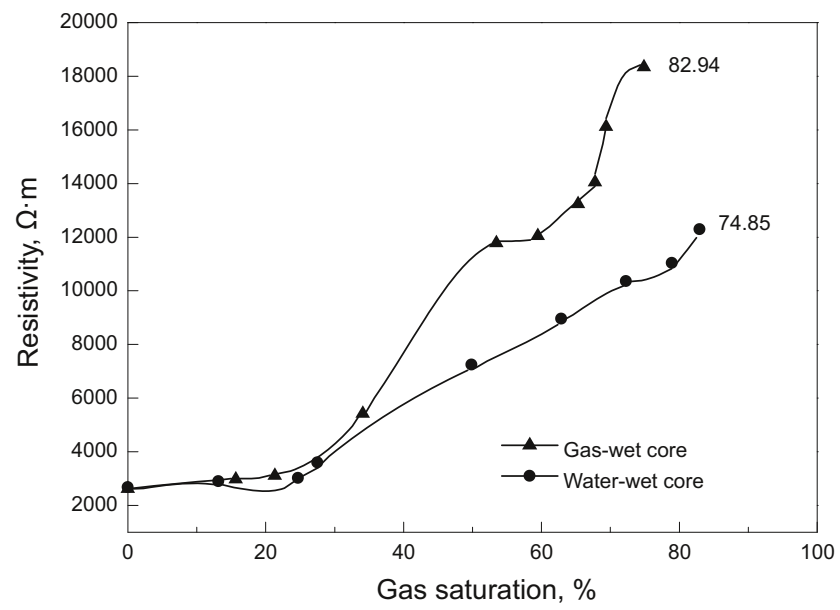

Fig. 13 Core resistivity at different gas saturations

resistivity values of both water-wet and gas-wet core samples were very high, but the conductive path was completely different. In the water-wet core samples with very low water saturation, a thin water film would be formed on the pore surface and this was the conductive path. The water film had a relatively high resistivity because of its small cross-sectional area and long length. In the gas-wet core samples with very low water saturation, the non-wetting phase, formation water, was located in branched pores in the form of isolated water droplets and had no contribution to the conductivity (Table 6).

Table 6 A comparison of water-wet and gas-wet core samples

\begin{tabular}{ccccc}
\hline $\begin{array}{c}\text { Core } \\
\text { sample }\end{array}$ & $\begin{array}{c}\text { Maximum gas saturation } \\
\%\end{array}$ & $\begin{array}{c}\text { Conductive paths } \\
\text { at low gas saturation }\end{array}$ & $\begin{array}{c}\text { Conductive paths } \\
\text { at high gas saturation }\end{array}$ & $\begin{array}{c}\text { Effect of simulation } \\
\text { formation water }\end{array}$ \\
\hline Water-wet sample & 74.8 & Connected water & Water film \& gas & Wetting phase \\
Gas-wet sample & 82.9 & Connected water & Isolated water \& gas & Nonwetting phase \\
\hline
\end{tabular}

\subsection{Spontaneous imbibition properties of rock samples}

Spontaneous imbibition refers to the wetting phase displacing the non-wetting phase in porous media under the control of capillary forces only (Bobek et al, 1958). If the imbibition of the wetting phase has the same direction as the displacement of the non-wetting phase, the process is defined as co-current spontaneous imbibition, otherwise as countercurrent spontaneous imbibition. Co-current and countercurrent spontaneous imbibition tests were conducted on the gas/liquid/rock systems. The effect of gas-wetting on velocity and induced gas recovery of spontaneous imbibition, and the trapped gas saturation by counter-current spontaneous imbibition were also investigated. Artificial sandstone cores prepared with quartz sand were used in this section to simulate natural cores (diameter $24.60-24.75 \mathrm{~mm}$, length $49.75-50.50 \mathrm{~mm}$, permeability $48.34-52.70 \mathrm{mD}$, porosity $11 \%-13 \%)$.

\subsubsection{Effect of gas wettability on co-current spontaneous imbibition}

As degree of wettability of the core samples to gas increased, the gas recovery by co-current imbibition gradually decreased and the velocity of imbibition declined, which made the equilibration time longer (Fig. 14). Gas recovery by co-current water imbibition was less than that by oil imbibition and the velocity of co-current oil imbibition was faster than that by water imbibition. FC-1-treated core samples showed stronger gas-wet properties in the gas/water/ rock system than that in the gas/oil/rock system.

\subsubsection{Effect of gas wettability on trapped gas saturation by} counter-current spontaneous imbibition

The relation between trapped gas saturation and FC-1 concentration was studied. Both in the gas/oil/rock and gas/ water/rock systems, the trapped gas saturation increased along with an increase in the FC-1 concentration. As well, the core samples treated with FC-1 solution had higher trapped gas saturation in the gas/water system than that in the gas/oil system (Fig. 15).

\section{Effect of gas wettability on capillary pressure, fluid flow and oil/gas/water distribution}

The effect of gas wettability on capillary pressure, fluid 


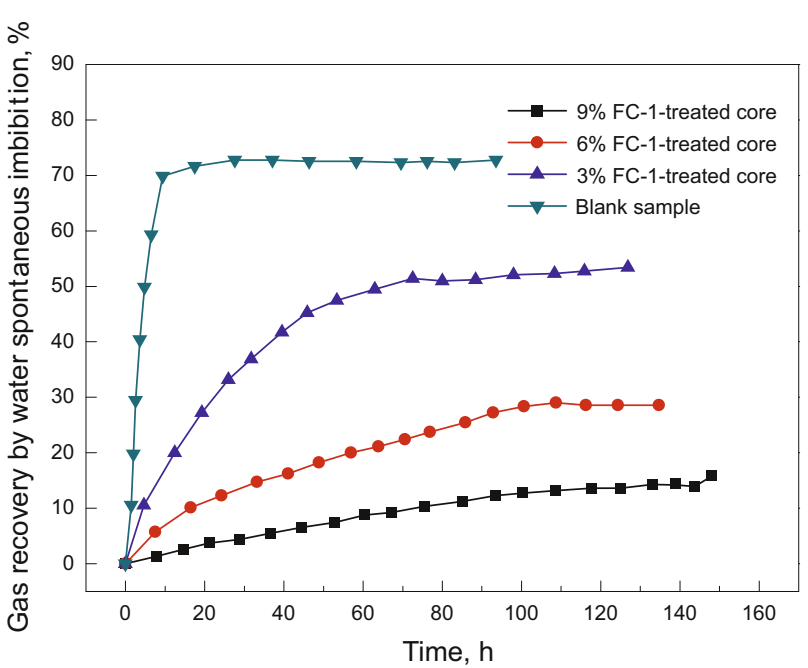

(a) Spontaneous oil imbibition

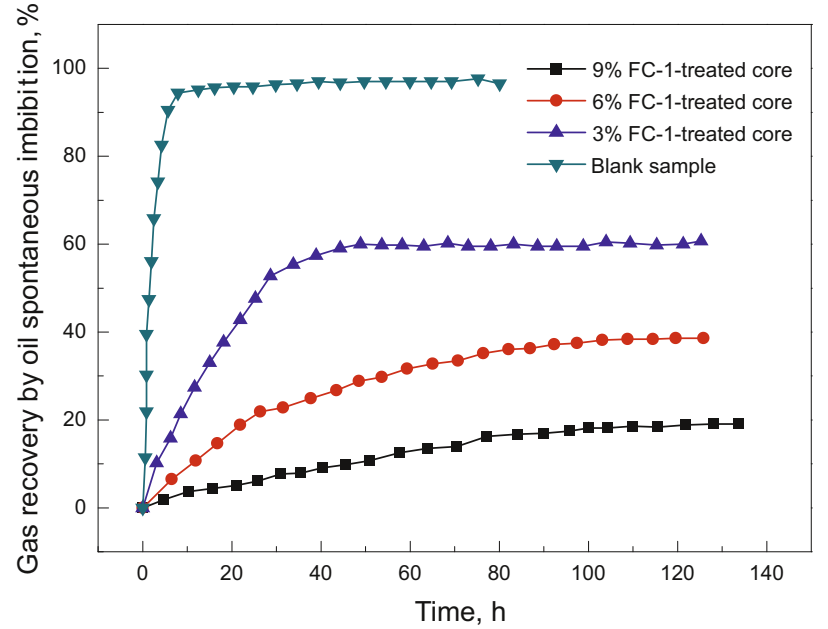

(b) Spontaneous water imbibition

Fig. 14 Gas recovery induced by spontaneous liquid imbibition into core samples with different degrees of wettability

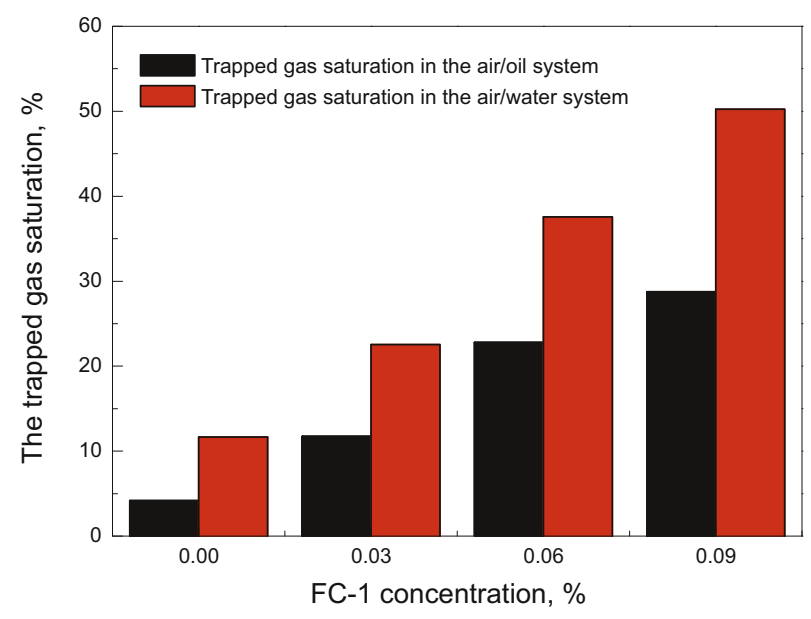

Fig. 15 Relation between trapped gas saturation and concentration of FC-1

flow and oil/gas/water distribution were studied with the capillary tubes and etched-glass network models of different wettability values.

\subsection{Capillary pressure}

Capillary tubes (micro-visual models) were used quite early to observe the wettability visually. Under quasi-static conditions, the core displacement tests were carried out both in gas/water and gas/oil system, in order to investigate the effect of gas wettability on the shape of displacement front and fluid distribution.

\subsubsection{Gas-water displacement tests in capillary tubes}

Under quasi-static conditions, displacement tests were conducted in capillary tubes at a water injection rate of 0.3 $\mathrm{mL} / \mathrm{h}$. The displacement front in capillary tubes of different wettabilities showed different curve shapes as the capillary pressure varied. The displacement fronts in capillary tubes treated with $0 \%, 0.2 \%$ and $8 \% \mathrm{FC}-1$ solutions are shown in Fig. 16.

The displacement front was concave in the non-gas-wet capillary tube, planar in the intermediately gas-wet capillary tube, and convex in preferentially gas-wet one. The direction of the capillary force in different wettabilities is also shown in Fig. 16. Capillary force played a role in the process of displacing gas in the non-gas-wet capillary tube with water, but had no effect on displacement in the intermediately gaswet capillary tube. Under the condition of preferentially gaswet, the capillary force was the resistance to gas displacement.

\subsubsection{Water-gas displacement tests in capillary tubes}

Water was displaced by gas in the capillary tubes of different wettabilities under quasi-static conditions and the results were shown in Fig. 17. The contact angle of this experiment was examined with the measuring software and photogoniometric method.

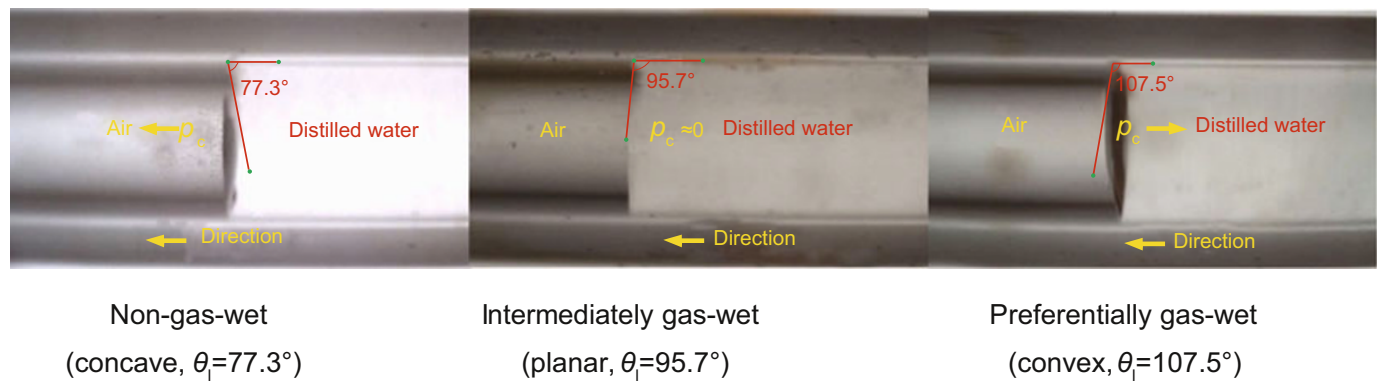

Fig. 16 Water displacement fronts in capillary tubes of different wettabilities 
The shape of the displacement front varied in capillary tubes of different gas wettabilities, and the advancing angle $\theta_{\mathrm{g}}$ decreased with an increase in the degree of gas wettability. Under non-gas-wet conditions, the mobility of water increased along with the decrease in $\theta_{g}$, and the resistance to gas flow reduced. When a water block occurs near the well bore in condensate gas reservoirs, utilizing the gas wettability chemical, FC-1, is an advisable method to relieve and remove the water block formation damage, and recover or maintain the gas well productivity.

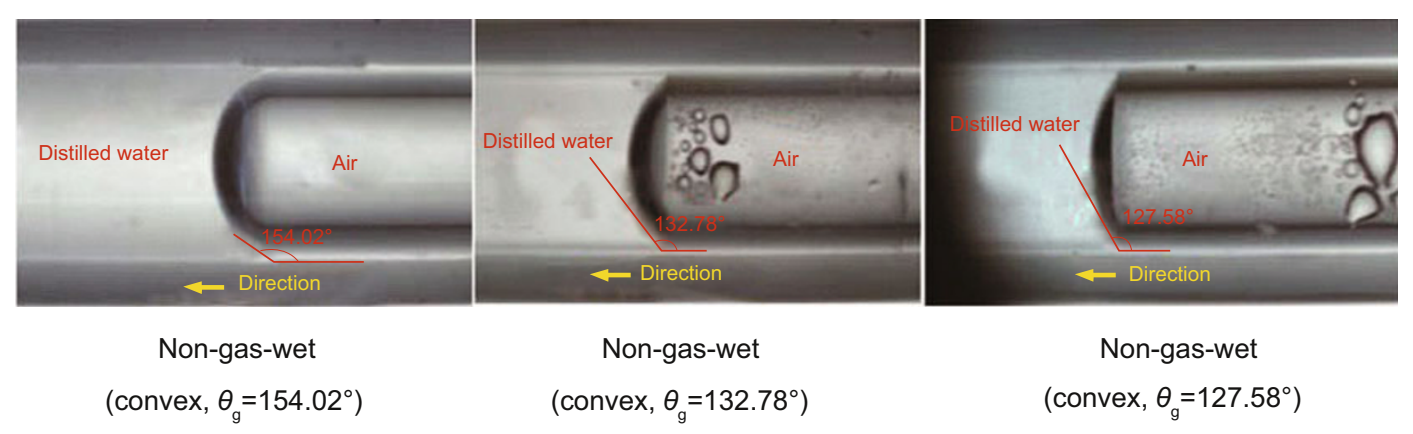

Fig. 17 Gas displacement fronts in capillary tubes of different wettabilities

\subsection{Flow state of gas/water in etched-glass network models of different wettabilities}

\subsubsection{Gas/water flow in gas-wet and non-gas-wet media}

The flow of gas/water in porous media is the theoretical foundation for the development of gas reservoirs by water drive, and wettability has a significant impact on gas/water flow in porous media. The effect of wettability on gas/water flow and the distribution of gas and water were studied with glass-etched network models of different wettabilities. The glass-etched network model was a transparent network structure patterned with tiny pores and channels by ultraviolet lithography technique, as shown in Fig. 18. In this model, 9 longitudinal capillary tubes were arranged crosswise of 8 transversal capillary tubes, thereof generating 72 nodes in the model. The diameter of the thicker capillary tube in the middle of the model was $0.2 \mathrm{~mm}$, and the pore diameter was $0.92 \mathrm{~mm}$. The diameter of other capillary tubes around the thicker one was $0.12 \mathrm{~mm}$, and the pore diameter was $0.5 \mathrm{~mm}$. The area of the model except pores was $32.36 \mathrm{~mm}^{2}$.

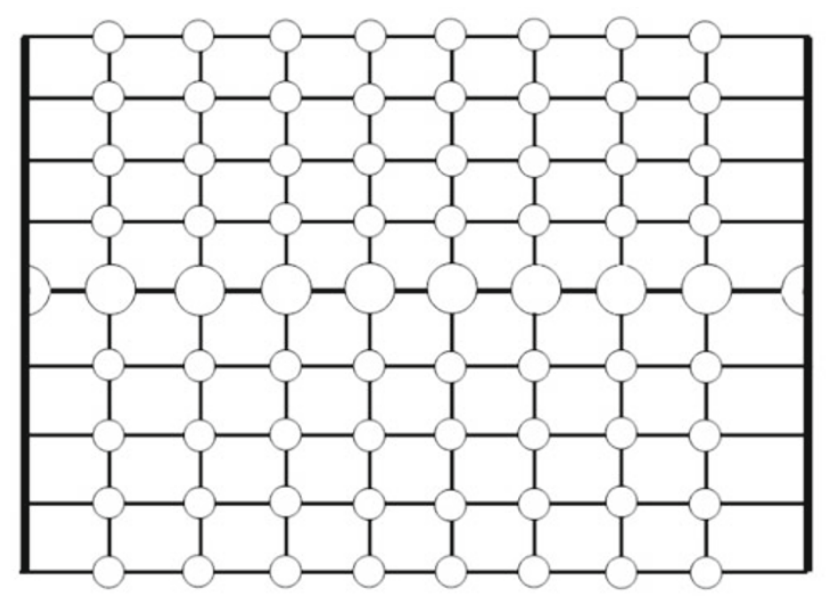

Fig. 18 Schematic plot of glass-etched network model with an ideal pore structure
In the non-gas-wet (hydrophilic, water-wet) model, spontaneous imbibition occurred immediately as water entered the groove, and water passed along the wall of porous channels to the model end instantaneously. The displacement was non-piston-like, and water preferentially went into pores and pore throats along the wall of porous channels. The displacement front was concave (Fig. 19(a)).

In the intermediately gas-wet model, water passed homogeneously and the displacement was piston-like, in which gas was thoroughly displaced. The water displacement front was planar, and the capillary pressure was zero (Fig. 19(b)).

In the preferentially gas-wet model, the water went in the center of porous channels and into the junctions of channels. The displacement front was convex (Fig. 19(c)).

\subsubsection{Gas/oil flow in gas-wet and non-gas-wet media}

There is very serious spontaneous imbibition in the nongas-wet (oleophylic, oil-wet) etched-glass network model. Oil went preferentially into the model along the wall of porous channels in a non-piston-like way, and the displacement front was concave (Fig. 20(a)).

In the intermediately gas-wet model, oil went into the porous channels to drive the gas in a piston-like way, and the displacement front was planar (Fig. 20(b)).

The displacement front was convex in the preferentially gas-wet model. A gas film was formed on the wall of pores and a gas film was observed at the displacement front (Fig. 20(c)).

\subsubsection{Oil/gas/water distribution in etched-glass network models}

In the non-gas-wet etched-glass network model, gas was continuously distributed in the middle of pores surrounded by liquids (Fig. 21(a)). The intermediately gas-wet model was almost saturated with liquid, and little residual gas was left in the model (Fig. 21(b)). In the preferentially gas-wet model, the liquid was distributed in the middle of the pores and the gas adhered to the wall of the porous channels like a film (Fig. 21(c)). 


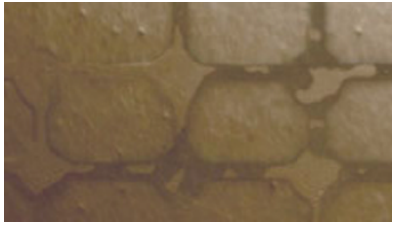

(a) Non-gas-wet (hydrophilic)

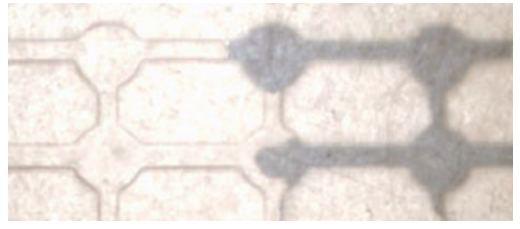

(b) Intermediately gas-wet

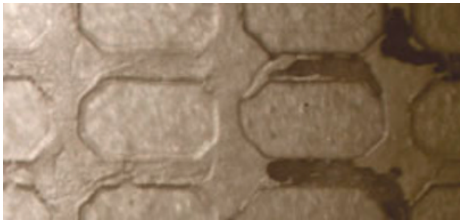

(c) Preferentially gas-wet

Fig. $19 \mathrm{Gas} /$ water flow state in gas-wet etched-glass network models

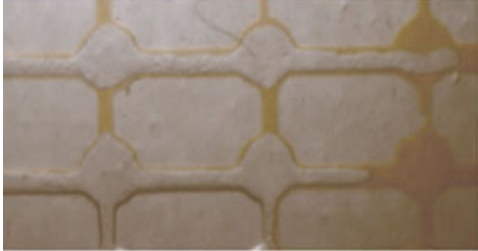

(a) Non-gas-wet (oleophylic)

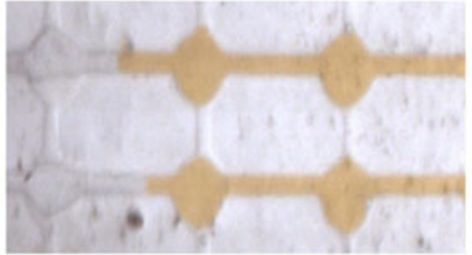

(b) Intermediately gas-wet

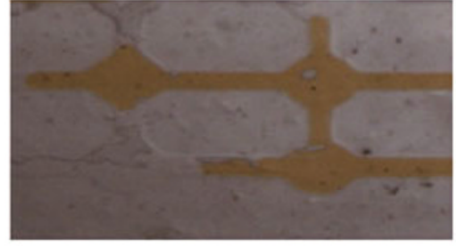

(c) Preferentially gas-wet

Fig. 20 Gas/oil flow in etched-glass models

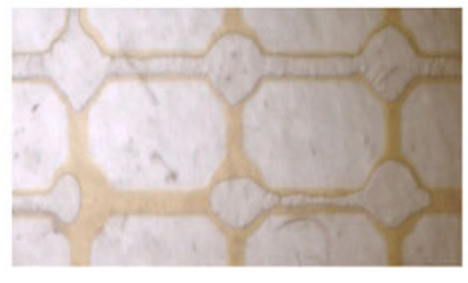

(a) Non-gas-wet

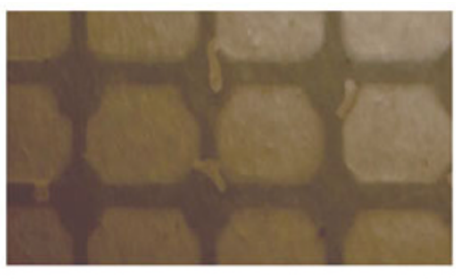

(b) Intermediately gas-wet

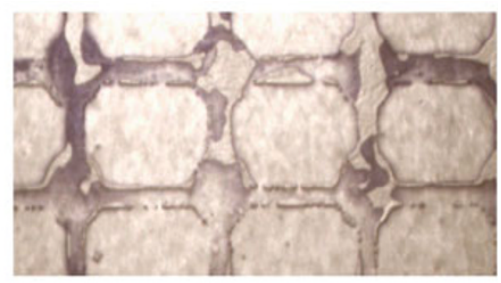

(c) Preferentially gas-wet

Fig. $21 \mathrm{Oil} / \mathrm{Gas} /$ water distribution in different models

\section{Conclusions}

1) Gas wettability is defined as the displacement ability of the gas phase over the liquid phase and this may reduce the surface free energy of the solid. Two evaluation methods were used: the sessile drop method and the captive bubble method.

2) The gas wettability was enhanced by a decrease in the solid surface free energy. When the surface free energy of solid was lower than that of the solid/liquid interface, and the adhesion work was negative, the solid was preferentially gaswet; otherwise, the solid was non-gas-wet (liquid-wet).

3) A novel fluorocarbon gas wettability alteration chemical, FC-1, was synthesized with core-shell copolymerization, which had a good wettability alteration ability. The mechanism of FC-1 altering rock wettability was a surface oriented phenomenon of fluorocarbon groups.

4) The gas wettability alteration to rock restrained clay hydration and swelling, changed the conductive path, reduced gas recovery due to co-current spontaneous imbibition and the velocity of co-current oil imbibition, and enhanced the trapped gas saturation.

5) Gas wettability had a significant effect on the shape of the displacement front, and the direction and magnitude of capillary force.

6) Displacing gas by liquid in the gas/liquid system was conducted with an etched-glass network models of different wettabilities. The effect of gas wettability on the displacement front and state, and the liquid distribution were also investigated.

\section{Acknowledgements}

This work is supported by the Basic Research on Drilling \& Completion of Critical Wells for Oil \& Gas (Grant No. 51221003), National Science Fund for Petrochemical Industry (Project No. U1262201), "863" National Project (Project No. 2013AA064803), National Science Fund for Distinguished Young Scholars (Project No. 50925414) and National Natural Science Foundation (Project No. 51074173).

\section{References}

Al-Anazi H A, Xiao J J, Al-Eidan A A, et al. Gas productivity enhancement by wettability alteration of gas-condensate reservoirs. Paper SPE 107493 presented at European Formation Damage Conference, 30 May-1 June 2007, Scheveningen, The Netherlands

Anderson W G. Wettability literature survey—part 1: rock/oil/brine interaction and the effects of core handling on wettability. Journal of Petroleum Technology. 1986. 38(10): 1125-1144

Bobek J E, Mattax C C and Denekas M O. Reservoir rock wettabilityits significance and evaluation. Petroleum Transaction, AIME. 1958. 213: $155-160$

Briant J and Cuiec L. Comptes-Rendus du 4ème Colloque ARTEP, Rueil-Malmaison, 7-9 Juin 1971. Paris: Ed. Technip. In Proceedings of the 4th ARTEP Symposium, Editions Technip, Paris, 1971

Buckley J S, Bousseau C and Liu Y. Wetting alteration by brine and 
crude oil: from contact angles to cores. Paper SPE 30765 presented at the 1995 Annual Technical Conference and Exhibition, 22-25 October 1995, Dallas

Buckley S E and Leverett M C. Mechanism of fluid displacement in sands. Trans. AIME. 1942. 146: 107

Chen H L and Monger-McClure T G. Determination of relative permeability and recovery for North Sea gas condensate reservoirs. Paper SPE 30769 presented at SPE Annual Technical Conference and Exhibition, 22-25 October 1995, Dallas, Texas

Cockcroft P J, Guise D R and Waworuntu I D. The effect of wettability on estimation of reserves. Paper SPE 19484 presented at the 1989 SPE Asia-Pacific Conference, 13-15 September 1989, Sydney

Donaldson E C and Thomas R D. Microscopic observations of oil displacement water-wet and oil-wet systems. Paper SPE 3555 presented at the 1971 Annual Meeting, 3-6 October 1971, New Orleans

Fahes $\mathrm{M}$ and Firoozabadi A. Wettability alteration to intermediate gaswetting in gas-condensate reservoirs at high temperatures. Paper SPE 96184 presented at SPE Annual Technical Conference and Exhibition, 9-12 October 2005, Dallas, Texas

Feng C Y, Kong Y, Jiang G C, et al. Wettability modification of rock cores by fluorinated copolymer emulsion for the enhancement of gas and oil recovery. Applied Surface Science. 2012. 258(18): 70757081

Froning H R and Leach R O. Determination of chemical requirements and applicability of wettability alteration flooding. Journal of Petroleum Technology. 1967. 19(6): 839-843

Jia D, Buckley J S and Morrow N R. Control of core wettability with crude oil. Paper SPE 21041 presented at the 1991 SPE International Symposium on Oilfield Chemistry, 20-22 February 1991, Anaheim, California

Jiang M. Effect of wettability of reservoir rocks on oil recovery. Petroleum Geology and Recovery Efficiency. 1995. 2(3): 25-31 (in Chinese)

Kamath K I S. A fresh look at wettability detergent flooding and secondary recovery mechanisms. Paper SPE 2862 presented at the 1970 SPE Biennial Production Techniques Symposium, 14-15 May 1970, Wichita Falls, Texas

Krasowaka M, Zawala J and Malysa K. Air at hydrophobic surfaces and kinetics of three phase contact formation. Advances in Colloid and Interface Science. 2009. 147-148(March-June ): 155-169

Lehmer H J, Rama R V V V N S, Nauduri D, et al. Synthesis and structure of environment tally relevant perfluorinated sulfonamides. Journal of Fluorine Chemistry. 2007. 128(6): 595-607

Li K W and Firoozabadi A. Phenomenological modeling of critical condensate saturation and relative permeabilities in gas condensate systems. SPE Journal. 2000a. 5(2): 138-147

Li K W and Firoozabadi A. Experimental study of wettability alteration to preferential gas-wetting in porous media and its effects. SPE Reservoir Evaluation \& Engineering. 2000b. 3(2): 139-149

Li K W and Horne R H. A wettability evaluation method for both gas-liquid-rock and liquid-liquid-rock systems. Paper SPE 80233 presented at SPE International Symposium on Oilfield Chemistry, 5-7 February 2003, Houston, Texas

Liu Y J, Zheng H W, Huang G X, et al. Production enhancement in gascondensate reservoirs by altering wettability to gas wetness: field application. Paper SPE 112750 presented at SPE/DOE Symposium on Improved Oil Recovery, 20-23 April 2008, Tulsa, Oklahoma, USA

Liu Y, Zheng H, Huang G, et al. Improving production in gas/condensate reservoirs by wettability alteration to gas wetness. Paper SPE presented at SPE/DOE Symposium on Improved Oil Recovery, 22-
26 April 2006, Tulsa, Oklahoma

Menezes J L, Yan J and Sharma M M. The mechanism of wettability alteration due to surfactants in oil-based muds. Paper SPE 18460 presented at the 1989 SPE International Symposium on Oilfield Chemistry, 8-10 February 1989, Houston

Morris E E and Wieland D R. A microscopic study of the effect of variable wettability conditions on immiscible fluid displacement. Paper SPE 704 presented at the 1963 Annual Technical Conference and Exhibition, 6-9 October 1963, New Orleans

Morrow N R, Cram P J and McCaffery F G. Displacement studies in dolomite with wettability control by octanoic acid. SPE Journal. 1973. 13(4): 221-232

Morrow N R. Wettability and its effect on oil recovery. Journal of Petroleum Technology. 1990. 42(12): 1476-1484

Noh $\mathrm{M}$ and Firoozabadi A. Wettability alteration in gas-condensate reservoirs to mitigate well deliverability loss by water blocking. SPE Reservoir Evaluation \& Engineering. 2008. 11(4): 676-685 (paper SPE 98357)

Ogunberu A L and Ayub M. The role of wettability in petroleum recovery. Petroleum Science and Technology. 2005. 23(2): 169-188

Panga M K R, Ismail S, Cheneviere P, et al. Preventive treatment for enhancing water removal from gas reservoirs by wettability alteration. Paper SPE 105367 presented at the 15th SPE Middle East Oil \& Gas Show and Conference, 11-14 March 2007, Kingdom of Bahrain

Panga M K R, Ooi Y S, Koh P L, et al. Wettability alteration for waterblock prevention in high-temperature gas wells. Paper SPE 10082 presented at SPE Europec/EAGE Annual Conference and Exhibition, 12-15 June 2006, Vienna, Austria

Penny G S, Soliman M Y and Briscoe J E. Enhanced load waterrecovery technique improves stimulation results. Paper SPE 12149 presented at the 1983 Annual Technical Conference and Exhibition, 5-8 October 1983, San Francisco

Shao C J, Li Z H, Wang X Y, et al. Pore network modeling for the investigation of factors affecting relative permeability of lowpermeability reservoirs. Natural Gas Industry. 2010a. 30(7): 36-38 (in Chinese)

Shao C J, Yang Z Q, Zhou G G, et al. Pore network modeling of water block in low permeability reservoirs. Petroleum Science. 2010b. 7(3): 362-366

Tang G Q and Firoozabadi A. Relative permeability modification in gasliquid systems through wettability alteration to intermediate gaswetting. SPE Reservoir Evaluation \& Engineering. 2002. 5(6): $427-$ 436 (paper SPE 81195)

Wagner O R and Leach R O. Improving oil displacement efficiency by wettability adjustment. Paper SPE 1101-G presented at the 1958 Annual Meeting, 5-8 October 1958, Houston

Wang Y F, Xu H M, Yu W Z, et al. Surfactant induced reservoir wettability alteration: recent theoretical and experimental advances in enhanced oil recovery. Petroleum Science. 2011. 8(4): 463-476

Yao T Y, Li J S and Yao F Y. Effects of gas-wetting on porous flow behavior in a gas-condensate reservoir. Oilfield Chemistry. 2008. 25(2): 101-104, 12 (in Chinese)

Zhou Z K, Gu T R and Ma J M. Fundamental Colloid Chemistry. Beijing: Peking University Press. 1987: 128-129 (in Chinese)

Zhu B Y and Zhao Z G. Fundamental Interface Chemistry (1st Edition). Beijing: Chemical Industry Press. 1996: 205-209 (in Chinese)

Zisman W A. Relation of the equilibrium contact angle to liquid and solid constitution. In: Contact Angle, Wettability, and Adhesion. Washington, DC: American Chemical Society. 1964. 1-51

(Edited by Sun Yanhua) 